\title{
The Pliability of the Joints of Wooden Elements in the Work of Wooden Reinforced Stress Ribbon Structures
}

\author{
Kravz Andrii, \\ Senior Lecturer. National Academy Fine Arts and Architecture \\ orcid.org/0000-0002-9585-1654 (Kyiv, Ukraine) \\ Demchyna Bohdan, \\ Doctor of Engineering, Professor. National University «Lviv Polytechnic» \\ ORCID:0000-0002-3498-1519 (Lviv, Ukraine)
}

\begin{abstract}
The behavior of a wooden stress ribbon structures reinforced with steel rope under the action of a load evenly distributed along the entire length of the cable was investigated. The analysis of the results of static tests of the wooden reinforced cable is given.

To ensure the stability and geometric invariance of the structures formed by rigid threads, an important role is played by taking into account the pliability of the nodal joints of the wooden elements of the cable. Based on this, the deformability of the joints of the wooden elements of the cable on the three type of joints and its effect on the deflection of the cable were investigated. The coefficient of deformability of joints was suggested, which took into account the nonlinear dependence of the deformation of joints of wooden elements of the cable on the applied load.

Deflections of wooden stress ribbon structures reinforced with steel rope are calculated taking into account the pliability of joints of individual wooden elements. The results of calculations are compared with experimental data.

Keywords: Suspension roof, wooden structures, rigid threads, stress ribbon, pliability of supports, static calculation, load, punched metal plate fasteners, joints of wooden elements.

Актуальність дослідження. Ключовою проблемою застосування висячих покриттів є задача підвищення їх жорсткості. До числа перспективних напрямків по вирішенню даної проблеми відносять розробку покриттів з використанням розтягнутих згинальножорстких ниток. На сьогоднішній день найбільш широкого застосування знайшли жорсткі ванти виконані у вигляді зігнутих ферм та зварних або прокатних двотаврів із маловуглецевої або низьколегованої сталі. Проте використання маловуглецевої або низьколегованої сталі для вантових конструкцій в замін високоміцних канатів знижує несучу здатність покриття, окрім того зростає власна вага покриття, що призводить до збільшення витрат матеріалів на усі опорні конструкції.

Для рішення цієї проблеми пропонується спільне застосування дерев'яних елементів та канатів, коли частину розтягуючих зусиль будуть нести сталеві канати, що мають великий розрахунковий опір на розтяг, а стабілізацію вант будуть забезпечувати дерев’яні елементи, з достатньо великою жорсткістю.
\end{abstract}


Аналіз останніх досліджень і публікацій. Попереднім аналізом літературних джерел, встановлено, що тема дерев'яних вант досліджувалась мало, хоча такий варіант збільшення жорсткості висячих конструкцій є досить ефективним, оскільки не значно збільшує власну вагу покриття через незначну об'ємну вагу деревини. Kristoffer Persson [1], Samuel Hofverberg [2], David Gustafsson, Martin Ingvarsson [3] та інші, дослідивши існуючі дерев'яні вантові конструкції, зробили висновок про необхідність подальших досліджень з'єднань дерев'яних елементів по довжині ванти. Методика досліджень дерев'яних армованих вант подана в роботах $[4,5]$. Результати експериментальних досліджень публікувались в роботах $[6,7,8,9]$.

Мета і задачі дослідження. Метою даного дослідження був розрахунок податливості з'єднань окремих дерев'яних елементів та аналіз його впливу на деформативність дерев'яних вант.

Виклад основного матеріалу. Відмінною ознакою між дослідними зразками вант різних серій була конструкція з'єднань дерев'яних елементів [4,5]. Дослідженню цього питання була приділена особлива увага. Це пов’язано з тим, що, відповідно до розрахунків [10], з'єднання елементів ванти повинно було стабілізувати канат, що потребувало сприйняття стискаючих та розтягуючих зусиль, а також моменту, який виникав від прикладання зовнішніх зусиль. У вузлах необхідно було забезпечити жорсткість з'єднання близьку до жорсткості дерев'яного тіла ванти.

Методика проведення випробувань. Дерев'яні елементи зразка серії ВД-1 з'єднувались між собою за допомогою металевих пластин товщиною 2мм, які прикріплювались до дошки саморізами $35 \times 3$ (рис. 1).

a)

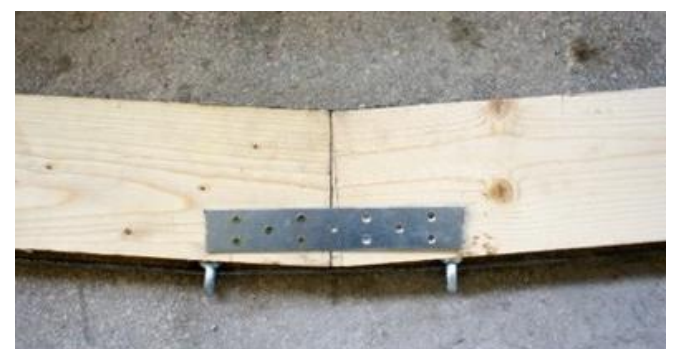

Рис. 1. 3'єднання дерев’яних елементів металевими пластинами;

а) загальний вигляд; б) конструктивна схема

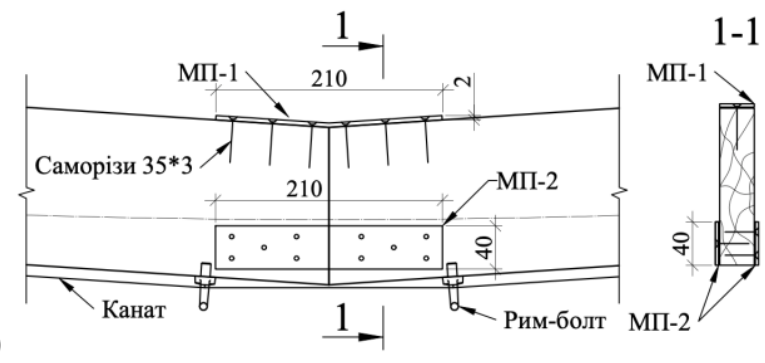
1-1 
3'єднання дерев'яних елементів ванти зразка серії ВД-2 були виконані за допомогою похиловклеєних стержнів по системі ЦНИИСК (рис. 2). Розрахунки елементів з'єднання були проведені відповідно до п.7.38-7.49 [11].

a)

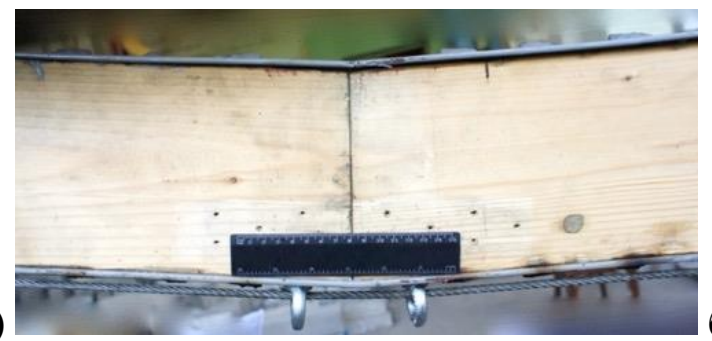

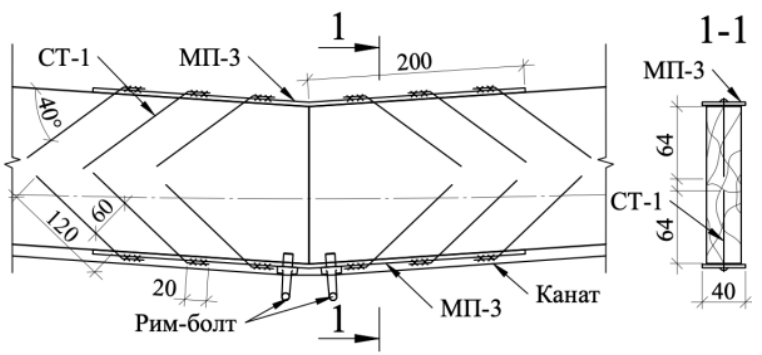

Рис. 2. 3'єднання дерев'яних елементів за допомогою похиловклеєних стержнів, та кріплення канату; а) загальний вигляд; б) конструктивна схема

Відповідно до програми експериментальних досліджень було розроблено третій тип з'єднання дерев'яних елементів для зразка ванти серії ВД-3 за допомогою металевих зубчатих пластин (МЗП) (рис. 3).

a)
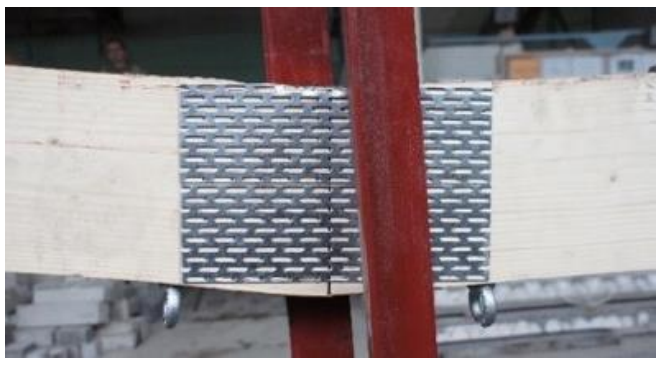

б)

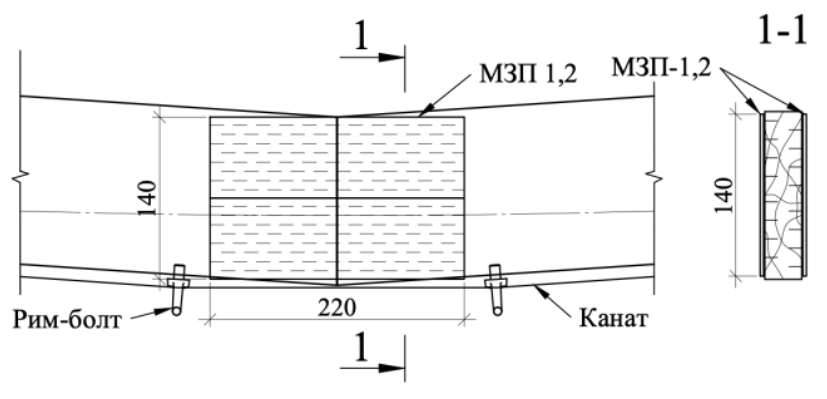

$1-1$

Рис. 3. 3'єднання дерев'яних дощатих елементів металозубчатими пластинами;

а) загальний вигляд; б) конструктивна схема

Досліджувана дерев'яна ванта складалась 3 п’яти дерев'яних елементів (рис. 4).

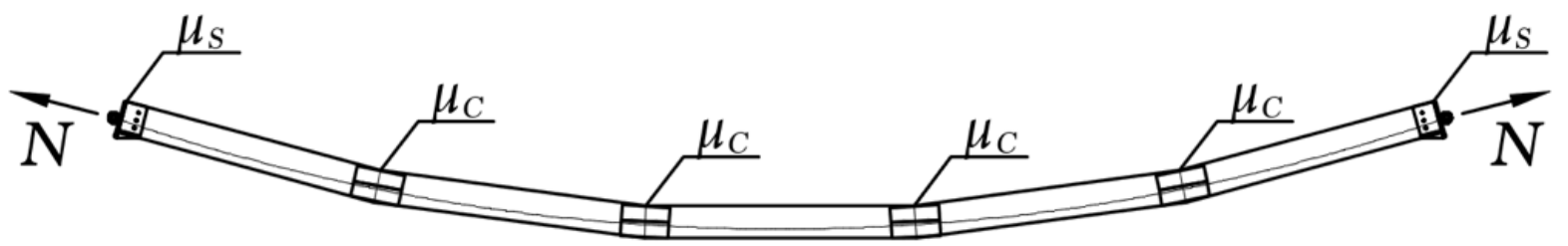

Рис. 4. Схема податливості з'єднань дерев'яних елементів ванти.

Результати досліджень. На рівні з податливістю опор [8], на роботу жорстких ниток впливає податливість з’єднань елементів конструкції.

Податливість з'єднань елементів ванти від приросту зусилля $\Delta N=1 \kappa \mathrm{H}$, обчислювалась за формулою: 


$$
\mu=2 \mu_{S}+4 \mu_{C}
$$

де $\mu_{S}=10^{-6} \mathrm{~m} / \mathrm{\kappa H}-$ експериментальне значення податливості опорного вузла дерев'яної ванти від $\Delta N=1 \kappa \mathrm{H}$;

$\mu_{\mathrm{C}}-$ податливість одного з'єднання дерев'яних елементів ванти від $\Delta N=1 \kappa \mathrm{H}$, визначена за результатами експериментальних досліджень на розтяг з'єднань дерев'яних елементів на металозубчастих пластинах (МЗП) (рис. 5):

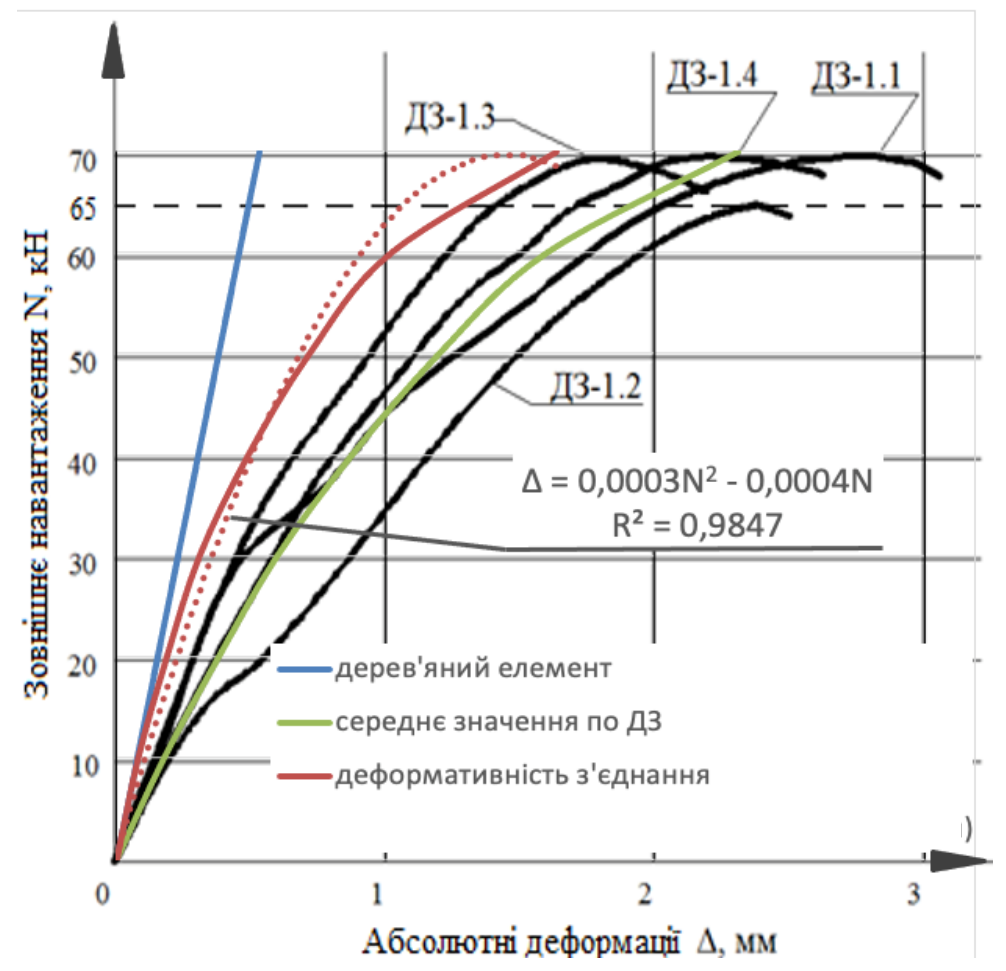

Рис. 5. Деформація з'єднання на МЗП.

Абсолютні деформації з'єднання на металозубчатих пластинах $(\Delta)$ визначались за квадратичною залежністю від розтягуючого зусилля $N$, з графіка деформації дослідних зразків ДЗ-1.1 - ДЗ-1.4. (див. рис. 5) [7].

$$
\Delta=0,0003 N^{2}-0,0004 N, \mathrm{MM}
$$

Відповідно, податливість з'єднання дерев'яних елементів ванти на МЗП від $\Delta N=$ 1кН визначалась:

$$
\mu_{\mathrm{C}}=\frac{\Delta}{N}=3 \cdot 10^{-7} \cdot N-4 \cdot 10^{-7} \mathrm{м} / \mathrm{\kappa H}
$$

Податливість з'єднань дерев'яних елементів вант інших серій визначались за аналогією до з'єднань на МЗП, враховуючи їхню пружно-пластичну роботу. Результати обчислень наведені в табл. 1 . 
Таблиця 1.

Деформативність 3'єднань дерев'яних елементів ванти

\begin{tabular}{|c|c|c|}
\hline Серія & Абсолютна деформація з'єднання $\Delta_{C}$, мм & Податливість зсднання $\boldsymbol{\mu}_{\mathrm{C}}, \mathbf{м м} / \mathbf{к H}$ \\
\hline ВД-1 & $0,003 N^{2}-0,07 N$ & $0,003 N-0,07$ \\
\hline ВД-2 & $0,001 N^{2}-0,01 N$ & $0,001 N-0,01$ \\
\hline ВД-3 & $0,0003 N^{2}-0,0004 N$ & $0,0003 N-0,0004$ \\
\hline
\end{tabular}

Отримані результати податливості з'єднань були використані для обчислення розрахункових значень прогинів дерев'яної армованої ванти в середині прольоту $\left(w^{\text {theor }}\right)$ від додаткового навантаження $(p=6 \kappa \mathrm{H} / \mathrm{M})$ :

$$
w^{\text {theor }}=\Delta \mathrm{L}_{\text {пр }} \frac{3}{16} \frac{l}{f_{0}}
$$

де $\Delta L_{\text {пр }}$ - приведене видовження ванти, яке складається з видовження тіла ванти, зближення опор і деформативності з'єднань дерев'яних елементів ванти:

$$
\Delta L_{\text {пр }}=\Delta L+v H+\mu N
$$

Видовження ванти від навантаження:

$$
\Delta L=\frac{N L}{E A}
$$

$L=l+\frac{8}{3} \cdot \frac{f_{0}^{2}}{l}=6+\frac{8}{3} \cdot \frac{0,5^{2}}{6}=6,1111 \mathrm{M}-$ початкова довжина ванти;

$l=6 \mathrm{M}-$ проліт ванти;

$f_{0}=0,5 \mathrm{M}$ - початкова стріла провису в середині прольоту від постійного навантаження $g$, що не викликало появи згинального моменту ванти;

Поздовжнє зусилля, що виникає у ванті від додаткового навантаження $(p, \kappa \mathrm{H} / \mathrm{M})$ :

$$
N=\sqrt{H^{2}+V^{2}}
$$

де $V=\frac{p l}{2}=\frac{6 \cdot 6}{2}=18$, кН - вертикальна опорна реакція;

$H$ - розпір ванти;

$v=v_{A}+v_{B}=6,75 \cdot 10^{-5}, \mathrm{м} / \kappa \mathrm{H}$ - податливість опор - експериментальне значення зближення опор $A$ та $B$ від $\Delta H=1 \kappa \mathrm{H}$;

$\mu=2 \mu_{S}+4 \mu_{C}-$ податливість 3'єднань дерев'яних елементів ванти від $\Delta N=1 \kappa \mathrm{H}$, приймалась згідно табл. 1; 
Для аналізу деформативності конструкції в залежності від типу з'єднання дерев'яних елементів було проведено аналіз прогинів в середині прольоту вант трьох серій від рівномірно розподіленого навантаження $p$ (рис. 6).

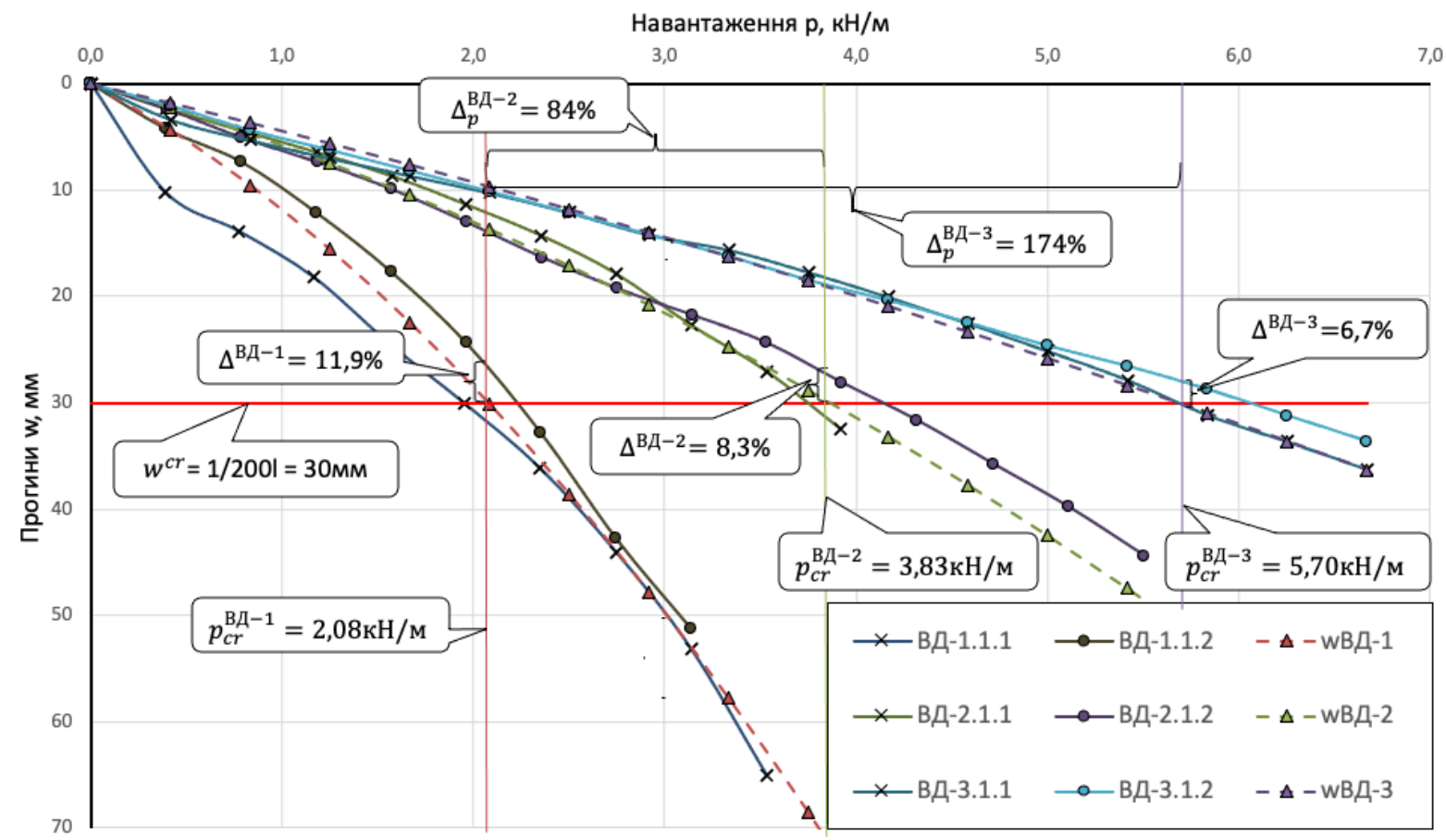

Рис. 6. Порівняння прогинів в середині прольоту вант трьох серій від рівномірно розподіленого навантаження $p$.

Як бачимо з графіків (рис. 6), прогини ванти при рівномірно розподіленому навантажені сильно залежать від податливості з'єднань. Так граничне навантаження при якому ванта досягала граничного прогину 30мм, для зразків серї ВД-2 та серії ВД-3 було на 84\% і 174\% відповідно, більше ніж для зразків серії ВД-1.

Експериментальні значення прогинів ванти 3 точністю до 11,9\% відповідають розрахунковим значенням, обчисленим з урахуванням податливості з'єднань дерев'яних елементів по відповідних серіях. Це підтверджує достовірність обчислених коефіцієнтів податливості з'єднань дерев'яних елементів та придатність методики розрахунку прогинів яка їх враховує.

\section{Висновки:}

1) 3 виконаного аналізу деформативності вант та дослідження окремих з'єднань, запропоновані коефіцієнти податливості з'єднань дерев'яних елементів, а саме:

- для з'єднання за допомогою металевих пластин $\mu=0,003 N-0,07$; 
- д для з'єднання на похиловклеєних стержнях $\mu=0,001 N-0,01$;

- для з'єднань на металозубчатих пластинах $\mu=0,0003 N-0,0004$.

2) Запропоновані коефіцієнти дали задовільну збіжність експериментальних i розрахункових прогинів серій: ВД-1 до 11,9\%, ВД-2 до 8,3\%, ВД-3 до 6,7\%.

\section{References}

1. Gustafsson, D. Ingvarsson M. "Application of Asymmetric Loads on Cable Shaped Structures" (2017). MA thesis. Chalmers University of Technology.

2. Hofverberg, S. (2016). Long-span tensile timber roof structures (Master's thesis, Chalmers University of Technology, Divison of Structural Engineering).

3. Persson, K.. (2018). "Analysis of Catenary Shaped Timber Structures.".

4. Kravz A.R. (2014). Metodyka eksperymental'nykh doslidzhen' derev'yanykh vant armovanykh stalevym kanatom zi z"yednannyam okremykh derev"yanykh elementiv metalorozdrukiv plastykamy [Methods of experimental research of wooden stress ribbon structures reinforced with steel rope with the connection of individual wooden elements with punched metal plate]. Perspektivnyye napravleniya innovatsionnogo razvitiya stroitel'stva $i$ podgotovki inzhenernykh kadrov: Sbornik nauchnykh statey XIX Mezhdunarodnogo nauchnometodicheskogo seminara; Brest 23-25.10.2014. - Brest: BrSTU,2014. - Part 1. 100-106. (in Ukrainian).

5. Kravz A.R., Demchyna B.G. (2013). Metodyka eksperymental'nykh doslidzhen' derev'yanykh vant armovanykh stal'nym kanatom zi z"yednannyam okremykh derev"yanykh elementiv vkleyenymy sterzhnyamy [Methods of experimental research of wooden stress ribbon structures reinforced with steel rope with the connection of individual wooden elements with glued rods]. Zbirnyk naukovykh prats' NUK 2, 38-42 (in Ukrainian).

6. Kravz A.R., Demchyna B.G. (2013). Eksperymental'ne doslidzhennya derev'yanykh vant armovanykh stal'nym kanatom zi z"yednannyam na vkleyenykh sterzhnyakh [Experimental research of wooden stress ribbon structures reinforced with steel rope with connection on glued rods]. Naukovo-tekhnichni problemy suchasnoho zalizobetonu. Vpusk 78. Knyha 2. K. DP NDIBK, 235-242 (in Ukrainian).

7. Demchyna B.G., Kravz A.R., Shidlovsky J., Yaremko I. (2014). Doslidzhennya na roztyah z"yednan' derev"yanykh elementiv na metalozubchastykh plastynakh (MZP) [Tensile tests of joints of wooden elements on punched metal plate]. Visnyk L'vivs'koho natsional'noho ahrarnoho universytetu. Seriya : Arkhitektura i sil's'kohospodars'ke budivnytstvo. - 15. 34-40 (in Ukrainian).

8. Kravz A.R., Demchyna B.G. (2020). Pidkhody do vrakhuvannya horyzontal'nykh peremishchen' fundamentiv v roboti derev"yanykh armovanykh vant. [Approaches to taking into account horizontal movements of foundations in the work of wooden reinforced cables]. Naukovo-tekhnichnyy zbirnyk «Osnovy ta fundamenty». Kyyiv: KNUBA, 2020. № 40. 51-64. (in Ukrainian).

9. Kravz A.R., Demchyna B.G. (2021) Vplyv velychyny poperedn'oho natyahu kanatu na napruzheno-deformovanyy stan derev'yanykh armovanykh vant. [Influence of the value of the 
pre-tension of the rope on the stress-strain state of wooden reinforced cables]. Theoretical and scientific bases of development of scientific thought: abstracts of reports of the International Scientific Conference on New Trends in Science and Education. ISBN 978-1-63684-356-8. DOI 10.46299/ISG.2021.I.V (Rome, Italy, 16 - 19.02.2021 p.). (in Ukrainian).

10. Svetnikov A. A. K voprosu ob ispol'zovanii prokatnykh profiley v kachestve materiala gibkikh nitey [On the question of using rolled profiles as a material for flexible threads] / A. A. Svetnikov. // Izv.vuzov. Stroitel'stvo. - 1996. - №8. - S. 3-6. (in Russian).

11. SNiP ÍÍ-25-80. Derevyannyye konstruktsii [Wooden structures] / Gosstroy SSSR. M.: Stroyizdat, 1982. - 66. (in Russian). 